\title{
Implementing the OSCE in Nottingham
}

\author{
John Brewin and Roch Cantwell
}

\begin{abstract}
The undergraduate medical curriculum in Nottingham has recenilly undergone dramatic change in response to General Medical Council recommendations. As part of the changes, the examination procedure in poychiatiry has been alfered, replacing the clinical 'long case' with an objective structured clinical examination (OSCE). The OSCE has long been seen as a valuable assessment tool in more 'procedureorlentated' specialities, but ths use in psychiatiry is not widely reported. This paper discusses the reasons behind the change, the design and implementation of the OSCE, and benefits and problems encountered during lts first application.
\end{abstract}

With changes in undergraduate medical education greater emphasis has been placed on learning objectives and self-directed learning. The impetus for change has come from General Medical Council (GMC) recommendations contained in Tomorrow's Doctors, which sets out a template for the development of medical education into the next century (GMC, 1993). Curricula have been charged with focusing on the knowledge, skills and attitudes needed by doctors in their first postgraduate year (Sensky, 1994). This has led to a reappraisal of the core objectives of teaching in psychiatry, and the methods by which students are assessed on completion of clinical placements.

Nottingham's curriculum owed much to new teaching styles, yet many changes were still required to bring the undergraduate course into line with GMC guidelines. Changes introduced have previously been reported (Cantwell \& Brewin, 1995) and mention made of the development of a new clinical assessment procedure based on the objective structured clinical examination (OSCE). This exam format is commonly used in more 'procedure-orientated' specialities such as surgery and obstetrics, and its use in psychiatry infrequently reported (Famuyiwa et al, 1991). In this paper we will outline the changes needed to introduce the OSCE, and our experience of its first application.

The clinical component of the old examination comprised the case history of a patient, seen for one hour, and presented to two examiners. The second part of the viva was more generalised and depended on examiners' choice of topic. There were a number of problems inherent in the lack of standardisation. The student's performance may have been hampered by a particularly difficult (or even absent) patient. Some examiners had reputations for being too harsh or too lenient. The diversity of in-patient diagnoses had declined in line with reduced bed numbers and the move to community care. Thus, long cases were often patients with severe chronic psychotic illnesses, rather than the acute distressed, depressed or anxious patients more commonly seen in general medicine and general practice.

A majority of students achieved grades of B or $C$, which failed to reflect the range of ability within the class. As an interim measure more objective guidelines were introducted for the long case viva which then became semi-structured similar to the College's membership long case. However, great variability between examiners remained.

\section{The OSCE}

An OSCE had previously been introduced for Year 1 by the Behavioural Sciences section of the department. Thus information on basic structure and requirement for an OSCE, and some experience in its implementation was available. The design involved each student rotating through six stations of 10 minutes' duration. At each station a student would be examined by a single examiner. These numbers were relatively arbitrary but there is evidence to suggest that a large number of independent stations increases the reliability of the assessment (Harden, 1990). Each station had a specific task and set objectives both for the student and the examiner. Mark sheets were detailed and aimed to reduce subjective variability.

Twenty-four students were examined in one afternoon. Six tasks were devised and objectives drawn up. Each task was duplicated so that in total 12 examiners were required and 12 students engaged in the assessment at any one time. This was repeated twice, so that the total time, including a break, was 2 hours and 20 minutes for the whole exam. 


\section{The content}

At the beginning of their clinical placement, students are given specific learning objectives. They include that students should become competent at taking a psychiatric history and assessing mental states. They should learn to talk to distressed patients, diagnose common psychiatric disorders, and understand the basic principles of management, in particular, of psychiatric problems encountered in a general hospital setting. They should also know when to refer patients for a specialist opinion. The OSCE requires students to apply knowledge and skills to specific clinical situations, rather than to recite memorised lists of facts. Some stations included an assessment of the quality of students' interactions with a 'patient' or 'relative'. Six topics were selected around these objectives. Details of one station are given in the appendix.

\section{The outcome}

There has been a steep learning curve (for organisers) both in terms of the general running of the OSCE and the specific detail of each station. A large amount of space is required to run the exam and segregation is needed to prevent students meeting between stations. Accurate time keeping is essential. Trouble shooters (lecturers) enable lost and forlorn students to find the correct rooms and rotate appropriately through the exam.

The individual stations require considerable planning. The first attempt at a short video, in which students watched a patient interview and answered questions on aspects of the mental state, left too little time for students to complete the answer sheet. A question on the assessment of cognitive function proved too complicated and led to students failing to apply their knowledge to the specific clinical problem. Mark sheets need to be as uncontentious as possible, yet leave some degree of flexdbility. Attempts to mark empathy proved particularly difficult. Although objectives and examiners' instructions were clearly given in writing, in the heat of the exam these could be easily overlooked. It was clear that examiners needed further preparation in advance of the exam and a videoed mock station will be used to train examiners and help improve reliability in future.

The OSCE has generated a great deal of uncertainty and interest among students. Initial feedback suggests that it is a fair but taxing exam. Students face a new clinical challenge every 10 minutes and there is little time to rectify mistakes. In a long case viva, after a shaky start. a student may gain confidence and eventually successfully present a good case history. There is no mechanism for this in the OSCE.
We were unprepared for the difficulties students had in maintaining empathic styles and using language appropriate to the clinical situation. In part this related to students' uncertainty of the exam structure and their familiarity with more traditional formats, which require a direct relationship with the examiner and place a greater emphasis on factual information. The new curriculum emphasises a shift away from attempts to cover the whole course in a didactic fashion, concentrating instead on providing a core upon which students can build themselves. Care is needed to ensure that skills, as well as knowledge, are included in the core teaching. Unless specifically timetabled these areas can be easily overlooked.

\section{The future}

The introduction of the OSCE has resulted in a major change in emphasis in our examination. Students will now be examined on objectives set at the beginning of the course and will hopefully leave psychiatric training with abilities immediately relevant to their medical career. We are aware however that initial OSCE stations have been rather crudely designed and limited in ambition. As confidence grows the variety of tasks set will increase. Questions remain regarding the reliability of the OSCE in assessing students' ability. We plan an analysis of written exam scores with both the old viva and the new OSCE. Further outcome measures could include a comparison of grades obtained in final MB examinations with OSCE scores.

As the new course evolves so too will assessment procedures. Currently the written exam is accepted as being a fair, reliable and valid test. although this has never been proven. Continued questioning of our assessments may produce further changes that will complement the style of the new curriculum. For the present, the OSCE is a new and innovative exam for clinical psychiatry which provides variety and flexibility in assessing students despite its apparent rigidity in being strictly objective led.

\section{Appendix}

OSCE station-Actress playing the anxious mother of a patient with first episode schizophrenia.

Student information - Mark Wilson, a 22-yearold man, has been admitted with a six month history of auditory hallucinations and persecutory delusions. A probable diagnosis of schizophrenia is made and he is commenced on antipsychotic medication. Previously he had been well and the episode appeared to have been precipitated by a break-up with his girlfriend. 
Your team wishes him to remain on the ward to assess his response to treatment. His mother has come to see you. She is anxious about the diagnosis and wishes to have it explained. You should attempt to answer any questions Mrs Wilson asks.

Assessor instructions - An actress plays the part of Mrs Wilson, the mother of a newly diagnosed patient with schizophrenia. The student should answer her questions about the diagnosis, bearing in mind her anxiety.

The following questions will be asked in the course of the interview:

(1) “Doctor, I've been told Mark has schizophrenia. That sounds really frightening. What does it mean?"

(2) "He seems to think we're all against him. He even told me that I was trying to poison him. Sometimes I find him talking to himself. Why is he doing these things?"

(3) "How long will it take for him to get better?"

(4) "I've heard that schizophrenics are violent and dangerous, is this true?"

Marksheet - Objective not met (0), partially met (1). fully met (2), fully met and appropriate rapport and empathy achieved (3)

Introduction/setting relative at ease

$\begin{array}{llll}0 & 1 & 2 & 3\end{array}$

Explanation of schizophrenia

Explanation of persecutory delusions

Explanation of auditory hallucinations

Discussion of prognosis/ risk of relapse

$0 \begin{array}{llll}0 & 1 & 2 & 3\end{array}$

$\begin{array}{llll}0 & 1 & 2 & 3\end{array}$
Discussion of risk of violence/ aggression

$0 \begin{array}{llll}0 & 1 & 2 & 3\end{array}$

\section{Acknowledgements}

We would like to thank our colleagues Drs Swaran Singh. Bert Park and Helen Baxter for their help in designing OSCE stations and $\mathrm{Dr}$ Conor Duggan for his support and comments on the paper.

\section{References}

CANTwEL, R. \& BREWIN, J. (1995) The new undergraduate curriculum: implementing the changes in Nottingham. Psychiatric Bulletin, 19, 482-484.

FAMUYTWA, O. O.. ZACHARUh, M. P. \& ILechUKWU, S. T. (1991) The objective structured clinical examination in undergraduate psychiatry. Medical Education, 25. 45-50.

GENERAL MEDICAL COUNCL (1993) Tomorrow's Doctors: Recommendations on Undergraduate Medical Education. London: GMC.

HARDEN, R. M. (1990) Twelve tips for organizing an objectlve structured clinical examination (OSCE). Medical Teacher, 12, 259-264.

SENSKY, T. (1994) The place of the psychiatrist in the new undergraduate curriculum. Psychitatic Bulletin, 18. 557-559.

John Brewin, Consultant Psychiatrist, Department of Psychiatry, A Floor, South Block, Queen's Medical Centre, Nottingham NG7 2UH; and "Roch Cantwell, Consultant Psychiatrist, Department of Psychological Medicine, Academic Centre, Gartnavel Royal Hospital, 1055 Great Western Road, Glasgow G12 $\mathrm{OXH}$

-Correspondence 